\title{
Letters
}

\section{Food in the library}

To the Editor:

I read with interest the article entitled "No food, no drink, no noise" (February 1994) and I was amused by the author's innovative signs such as "Ravenous Roaches Ravage Rootbeer and Rare Books."

Two years ago our library ciropped its "no drink" policy and began allowing drinks in any kind of covered container. We also eased our "no food" policy, prohibiting only messy, smelly foods such as pizzas or hamburgers and fries, etc. We have even gone as far as to establish an annual Christmas party in the library. The library provides the drinks, cookies, snacks, and loud Christmas music. The students LOVE it!

In two years I have yet to see a roach in our library. In fact, I have detected no major spills, wet books, water rings, or any of the other nightmares librarians have about allowing food and clrink in the library.

In my judgment, this is a customer service issue. I want to do everything reasonable to make our students feel good about libraries. Allowing food and drinks has been a reasonable concession and, I believe, it has had very positive repercussions._Dennis Ingolfsland, Bryan College

\section{More women's studies resources on the Net...}

To the Editor:

I am writing in response to Mary Glazier's article, "Internet resources for women's studies" (March 1994). I have been doing research on women's studies and the Internet and was very glad to see such attention given to women's studies.

However, I would like to call your attention to an oversight in that article: since there are no databases/CD-ROMs dedicated to women's studies, and others may include only some women's studies journals, a database which includes almost all (over 80 ) such journals is CARL UnCover. CARL UnCover is available through the Internet by telnetting to uncover.carl.org. Also, a list I compiled of the women's studies-related journals on CARL UnCover and some search tips are available on the University of Maryland gopher. Telnet to inform.umd.edu, then choose 4. Educational Resources, 17. Women's studies, 11. Resources, then 6. Using CARL UnCover.

Access to women's studies information is a major concern of all librarians because women's studies has been integrated into all subjects, in particular literature, sociology, and psychology. CARL UnCover is a great resource for women's studies information.-Jill Morrissey, University of Connecticut

\section{... and another}

To the Editor:

As a women's studies librarian, I was very pleased to see Mary Glazier's article in the March 1994 issue of CERL News.

I must point out, however, that Glazier makes an unfortunate omission by neglecting to mention the Schlesinger Library on the History of Women in America in her section on OPACs.

The Schlesinger Library is one of the largest and best-known women's history libraries in the world. All of our holdings, including 50,000 books and 2,000 manuscript collections, are listed on Harvard's online catalog, HOLLIS. To access HOLLIS, teinet to HOLLIS.HARVARD.EDU. Press return for vt 100 terminals, or enter in another type. Select HOLLIS from the next ment. Our holdings are included in the HU database.-Wendy Thomas, Radcliffe College

\section{(Internet cont. from page 257)}

- The National Distance Learning Center Clearinghouse at Owenshoro Community College in Kentucky.

- The Centre for Distance Education at Athabasca University is creating a database of e-mail addresses of adult and distance education researchers in an effort to provide information and connections.

- At the University of Washington, IBM and the university maintain a Bulletin Board Service for educators which contains a conference on DE. It may be reached by telnet to isaac.engr.washington.edu or 128.95.32.61. This service requires registration. 


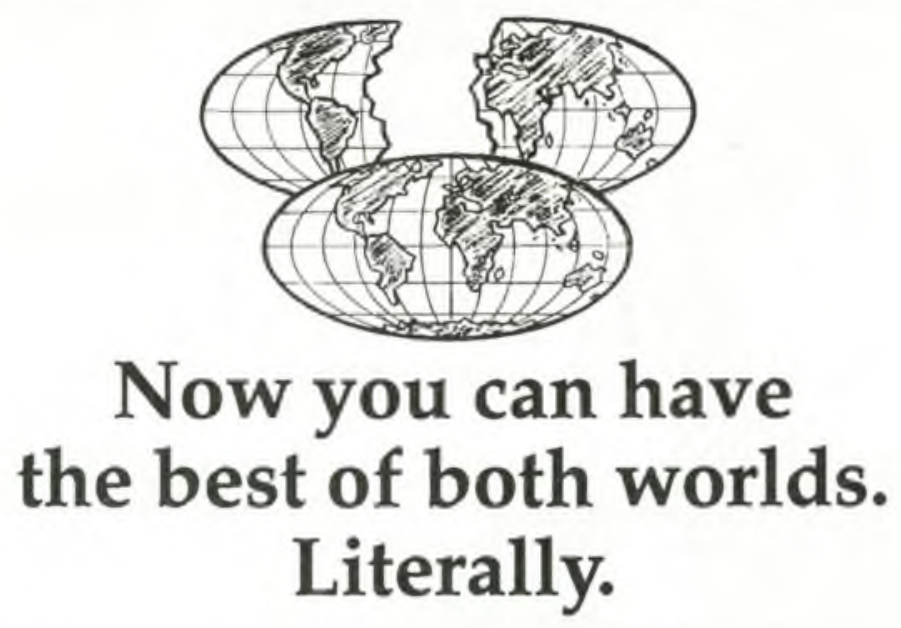

With EBSCO you can work with our regional office in your area to ensure convenience, timeliness and efficiency in your day-to-day subscription transactions. And you can count on our other offices located near the places most journals are published to assist in obtaining full service for your subscriptions. In most cases, you may not even be aware that EBSCO staff from a remote location are working for you as well as your local office. Our 17 non-North American offices throughout the world can help serve your needs for non-domestic serials, no matter where they originate. Plus, by using one capable serials vendor for all your titles, you benefit through increased internal efficiency and more valuable serials management reports.

Subscribe globally. Order locally. With EBSCO.

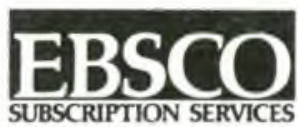

International Headquarters

P.O. Box 1943 • Birmingham, AL 35201-1943

(205)991-6600 • Fax (205)995-1636

EBSCO operates nine offices in the U.S, and two in Canada. Other offices located in: Australia, Brazil, Czech Republic, France, Germany, Hong Kong, Italy, Korea, The Netherlands, New Zealand, South Africa, Spain, Taiwan, Thailand, Turkey and the United Kingdom. 


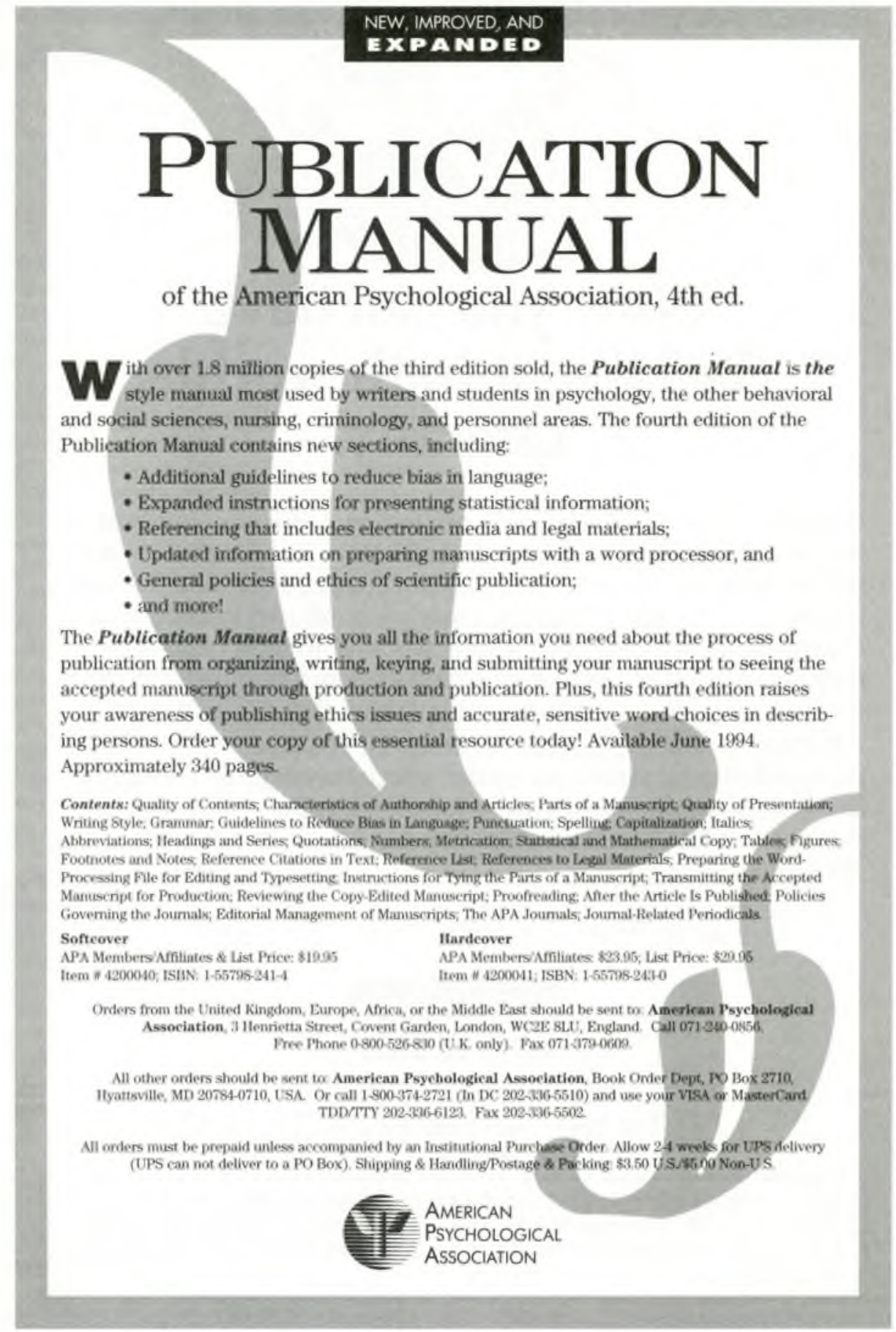

